\title{
Cytotoxic effect of trans-cinnamaldehyde on human leukemia K562 cells
}

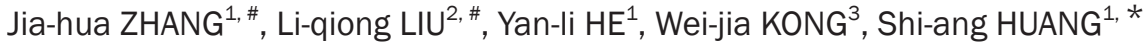 \\ ${ }^{1}$ Center for Stem Cell Research and Application, Union Hospital of Tongji Medical College, Huazhong University of Science and \\ Technology, Wuhan 430022, China; 'Department of Hematology, Nanshan People Hospital of Shenzhen, Shenzhen 518052, China; \\ ${ }^{3}$ Department of Otorhinolaryngology Head and Neck Surgery, Union Hospital of Tongji Medical College, Huazhong University of Sci- \\ ence and Technology, Wuhan 430022, China
}

Aim: To investigate the effects of trans-cinnamaldehyde (TCA) on the human leukemia K562 cell line and the cytotoxicity of cytokineinduced killer (CIK) cells against K562 cells.

Methods: Apoptosis, Fas expression, and mitochondrial transmembrane potential in K652 cells were analyzed using flow cytometry. K562 cells were labeled with CFSE. The cytotoxic effect of expanded CIK cells on CFSE-labeled K562 cells was determined by FACS flow cytometry.

Results: Treatment with TCA $180 \mu \mathrm{mol} / \mathrm{L}$ for $9 \mathrm{~h}$ induced apoptosis in $8.9 \% \pm 1.23 \%$ of K562 cells. Treatment with 120 or 180 $\mu \mathrm{mol} / \mathrm{L}$ TCA for $24 \mathrm{~h}$ significantly increased the apoptotic cells to $18.63 \% \pm 1.42 \%$ and $38.98 \% \pm 2.74 \%$, respectively. TCA significantly upregulates Fas expression and decreases mitochondrial transmembrane potential in K562 cells. TCA treatment at 120 and 180 $\mu \mathrm{mol} / \mathrm{L}$ for $9 \mathrm{~h}$ enhanced the percentage of lysis of $\mathrm{K} 562$ cells by expanded CIK cells from $34.84 \% \pm 2.13 \%$ to $48.21 \% \pm 2.22 \%$ and $64.81 \% \pm 3.22 \%$ at the $E: F$ ratio of $25: 1$ and from $49.26 \% \pm 3.22 \%$ to $57.81 \% \pm 5.13 \%$ and $73.36 \% \pm 5.98 \%$ at $E: F$ ratio of $50: 1$.

Conclusion: TCA exerts cytotoxic effects on human leukemia K562 cells by inducing apoptosis and synergizing the cytotoxicity of CIK cells against K562 cells. These properties of TCA are beneficial to the treatment of leukemia, even in the patients who have received hematopoietic stem cells transplantation (HSCT).

Keywords: trans-Cinnamaldehyde; leukemia; K562 cells; apoptosis; Fas; mitochondrial transmembrane potential; cytokine-induced killer cells

Acta Pharmacologica Sinica (2010) 31: 861-868; doi: 10.1038/aps.2010.76; published online 28 June 2010

\section{Introduction}

Although allogeneic hematopoietic stem cell transplantation (HSCT) is a highly effective treatment for leukemia, its therapeutic potential is counterbalanced by treatment-related toxicity, especially the development of graft-versus-host disease (GVHD) and relapse due to minimal residual leukemic cells remains, which are major complications and formidable obstacles $^{[1]}$. Many patients relapse with or die of GVHD, even after transplantation. The use of immunosuppressors against GVHD is not conducive to the absolute depletion of residual leukemic cells. Therefore, the development of appropriate anticancer drugs remains an important goal ${ }^{[2]}$.

Trans-Cinnamaldehyde (TCA), also known as cinnamaldehyde, is an active compound isolated from the stem bark of

\footnotetext{
\# These two authors contributed equally to this work.

* To whom correspondence should be addressed.

E-mail sa2huang@126.com

Received 2010-01-03 Accepted 2010-05-25
}

Cinnamomum cassia. The chemical structure of TCA is shown in Figure 1. TCA can be applied as a flavorant, an agrichemical, an antimicrobial and in miscellaneous uses, such as a corrosion inhibitor for steel and other ferrous alloys in corrosive fluids. With the exception of being a skin irritant, TCA has low toxicity. Recent documented data showed TCA could induce the apoptosis of several human tumor cell lines, including human promyelocytic leukemia HL-60 cells ${ }^{[3,4]}$. Interestingly, TCA has been shown to interfere with $\mathrm{T}$ cell activation through different mechanisms and could, therefore, have additive effects on the inhibition of $\mathrm{T}$ cell activation ${ }^{[5]}$. Activated $\mathrm{T}$ cells are well recognized as the first component of a

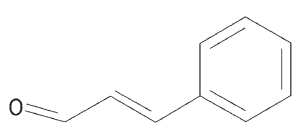

Figure 1. Chemical structure of TCA. 
GVHD reaction ${ }^{[6]}$. Thus, TCA may be a promising drug for modulating the immune response and dealing with relapse and GVHD.

Cytokine-induced killer (CIK) cells, derived from the peripheral blood of normal donors or leukemia/lymphoma patients, are $\mathrm{T}$ cells with a characteristic immunophenotype of CD3 and CD56 double positivity. Data show that CIK cells exhibit potent anti-tumor activity in vitro and in vivo, they do not interfere with bone marrow engraftment in vivo and have little GVHD activity in several allogeneic models ${ }^{[7]}$. In this study, we first investigate the effects of TCA on the apoptosis of K562 leukemic cells and the effect of TCA on the cytotoxicity of CIK cells against $\mathrm{K} 562$ cells. Our aim is to provide evidence for the development of TCA as an anticancer drug to treat leukemia, even in patients after HSCT.

\section{Materials and methods Reagents}

TCA $\left(\mathrm{C}_{9} \mathrm{H}_{8} \mathrm{O}\right.$, molecular weight $=132.16$, purity $\left.\geq 95 \%\right)$ was obtained from Sinopharm Chemical Reagent Co Ltd, China. A $200 \mathrm{mmol} / \mathrm{L}$ solution of TCA was prepared in dimethyl sulfoxide (DMSO) and stored in aliquots at $-20{ }^{\circ} \mathrm{C}$ until use. The final concentration of DMSO did not exceed $0.1 \%$ in any experiment. DMSO and propidium iodide (PI) were purchased from Sigma-Aldrich Inc, USA. Fetal bovine serum (FBS) and RPMI 1640 were purchased from Gibco-BRL Inc, USA. FicollHypaque $(1.077 \mathrm{~g} / \mathrm{mL})$ was purchased from Haoyang Biological manufacture Co, China. Fluorescein isothiocyanate (FITC) labeled anti-CD3 antibody (CD3-FITC), phycoerythrin (PE) labeled anti-Fas (CD95) and anti-CD56 antibodies (CD95-PE, CD56-PE) were obtained from BD PharMingen, USA. The Annexin-V/PI Staining Kit was purchased from Bender Medsystems Inc, Austria. Carboxyfluorescein succinimidyl ester (CFSE) was purchased from Molecular Probes, USA. AntiCD3 (Orthoclone OKT 3) was from Cilag GmbH, Germany. Interleukin-1 $\beta$ (IL-1 $\beta$ ) and interleukin-2 (IL-2) were purchased from R\&D Systems, Germany. Human recombinant interferon Y (IFN- $\gamma$ ) was purchased from Boehringer Mannheim, Germany.

\section{Cell culture}

The K562 cell line was obtained from the American Type Culture Collection, USA. Cells were cultured in complete medium (RPMI-1640 medium with 10\% FBS containing 100 $\mathrm{U} / \mathrm{mL}$ penicillin, $100 \mu \mathrm{g} / \mathrm{mL}$ streptomycin) at $37{ }^{\circ} \mathrm{C}$ in a $5 \%$ $\mathrm{CO}_{2}$ humidified atmosphere. The medium was changed every 2 days. The experiments were performed on cells during their exponential phase of growth.

\section{Apoptosis analysis by flow cytometry}

K562 cells were treated with various concentrations of TCA for 4, 9, or $24 \mathrm{~h}$. Cells were harvested and labeled with Annexin V conjugated with fluorescein isothiocyanate (Annexin V-FITC) and PI. The cells were then analyzed by flow cytometry. Apoptotic cells were defined as Annexin V-positive and PInegative cells (early apoptotic cells) plus Annexin V-positive and PI-positive cells (late apoptotic cells).

\section{Fas/CD95 expression analysis by flow cytometry}

After treatment with TCA for 4, 9, or 24 h, K562 cells were washed with PBS and incubated for $20 \mathrm{~min}$ on ice with PElabeled anti-Fas (CD95) antibody. Then, the cells were immediately analyzed by the flow cytometry.

\section{Mitochondrial transmembrane potential $(\Delta \psi \mathrm{m})$ analysis by flow cytometry}

After treatment with TCA for 24 h, K562 cells were washed with PBS and incubated for $15 \mathrm{~min}$ at $37{ }^{\circ} \mathrm{C}$ with $0.5 \mathrm{mg} / \mathrm{L}$ Rho123, a fluorescent staining dye used to evaluate the change of $\Delta \psi \mathrm{m}$. The cells were immediately analyzed by the flow cytometry.

\section{Generation and immunophenotype identification of ClK cells}

CIK cells were generated under good manufacturing practice conditions as previously described ${ }^{[8]}$. First, peripheral blood samples from five healthy donors were collected after obtaining informed consent. Mononuclear cells were isolated by Ficoll-Hypaque gradient purification as per the manufacturer's instructions. Peripheral blood mononuclear cells (PBMNCs) were grown in complete culture medium at $37{ }^{\circ} \mathrm{C}$ in a $5 \% \mathrm{CO}_{2}$ humidified atmosphere. At day $0, I^{2}-\gamma$ was added to the cells at a final concentration of $1000 \mathrm{U} / \mathrm{mL}$. After $24 \mathrm{~h}$ of incubation, $50 \mathrm{ng} / \mathrm{mL}$ of anti-CD3, $100 \mathrm{U} / \mathrm{mL}$ IL-1 $\beta$ and $300 \mathrm{U} /$ $\mathrm{mL}$ IL-2 were added. Cells were incubated and sub-cultured every third day in fresh complete medium containing IL-2 and anti-CD3 at $3 \times 10^{6}$ cells $/ \mathrm{mL}$. CIK cells were harvested on day +10 . Immunophenotypic identification of the PBMNCs on day 0 and CIK cells on day +10 was performed by FACS flow cytometry (Becton Dickinson). The percentages of lymphocytes expressing CD3CD56 molecules were determined at each time point.

\section{Cytotoxicity assay}

K562 cells were labeled with CFSE, a fluorescent live cellstaining dye, according to the original method described elsewhere and modified ${ }^{[9]}$. CFSE-labeled K562 cells were seeded at a density of $2 \times 10^{5}$ cells $/ \mathrm{mL}$ into a flask in complete medium and pretreated with TCA at a final concentration of 120 or $180 \mu \mathrm{mol} / \mathrm{L}$ for $4 \mathrm{~h}$. Following TCA exposure, the cells were reseeded in 24-well plates as the target cells (T) at a constant number of 60000 cells after two washes with complete medium. CIK cells were added as effector cells (E) into target cell cultures at one of two E:T ratios (25:1 or 50:1). In parallel, target cells were incubated alone to measure basal lysis. For the continuous TCA treatment group, TCA at a final concentration of 120 or $180 \mu \mathrm{mol} / \mathrm{L}$ was added into corresponding cultures. All cells were incubated for another $5 \mathrm{~h}$. Then, aliquots of freshly collected cells were centrifuged, washed in PBS and resuspended in PBS containing $25 \mu \mathrm{g} / \mathrm{mL}$ PI. After incubation for $20 \mathrm{~min}$ at room temperature in the dark, acquisition was performed without delay on a FACS flow cytometer. CFSE fluorescence and PI emission were detected using 
the FL-1 and FL-2 channels, respectively. At each E:T ratio (25:1 or 50:1), 5000 target cells were acquired. Analysis was performed with the Cell Quest software (Becton Dickinson).

\section{Statistical analysis}

All data are expressed as means \pm standard deviations (SD). Statistical analysis was performed using SPSS12.0. Differences between repeated experiments with variable concentrations of TCA were computed using the Student's $t$ test. $P<0.05$ was considered to be statistically significant.

\section{Results}

TCA induced apoptosis in K562 cells

K562 cells were treated with 120 or $180 \mu \mathrm{mol} / \mathrm{L}$ TCA. At 4, 9 , or $24 \mathrm{~h}$, cells were harvested for apoptosis analysis. At $4 \mathrm{~h}$, TCA did not significantly induce K562 cells apoptosis. At 9 h, $180 \mu \mathrm{mol} / \mathrm{L}$ TCA markedly induced K562 cells apoptosis $(8.9 \% \pm 1.23 \%)$. At $24 \mathrm{~h}$, TCA significantly increased the percentage of apoptotic cells in a dose-dependent manner (Figure 2 ). The apoptosis rate after treatment with 120 or $180 \mu \mathrm{mol} / \mathrm{L}$ TCA was $18.63 \% \pm 1.42 \%$ and $38.98 \% \pm 2.74 \%$, respectively. The spontaneous apoptosis rate was $3.56 \% \pm 0.72 \%$ in K562 cells.

\section{TCA upregulated Fas expression in K562 cells}

Fas/CD95 was not universally expressed in K562 cells, as described previously ${ }^{[10]}$. Exposure of K562 cells to TCA resulted in the expression of Fas/CD95 in K562 cells in a timedependent fashion and a dose-dependent manner (Figure 3). At $4 \mathrm{~h}, 180 \mu \mathrm{mol} / \mathrm{L}$ TCA upregulated Fas/CD95 expression in K562 cells. At $9 \mathrm{~h}$ and $24 \mathrm{~h}, 120$ and $180 \mu \mathrm{mol} / \mathrm{L}$ TCA significantly increased Fas/CD95 expression in K562 cells.

TCA decreased the mitochondrial transmembrane potential $(\Delta \Psi \mathrm{m})$ in $\mathrm{K} 562$ cells

K562 cells were treated with 120 or $180 \mu \mathrm{mol} / \mathrm{L}$ TCA for $24 \mathrm{~h}$. The mitochondrial transmembrane potential $(\Delta \psi \mathrm{m})$ in K562 cells was analyzed by flow cytometry. TCA at 120 and $180 \mu \mathrm{mol} / \mathrm{L}$ induced the loss of $\Delta \psi \mathrm{m}$ in K562 cells from $1.56 \% \pm 0.35 \%$ to $14.16 \% \pm 2.56 \%$ and $28.84 \% \pm 3.53 \%$, respectively.

\section{TCA synergized the cytotoxicity of ClK cells to K562 cells}

To characterize the expanded CIK cells, the immunophenotype of the expanded cells was determined using flow cytometry. The $\mathrm{CD}^{+}{ }^{+} \mathrm{CD} 56^{+}$subset of cells comprised just $1 \%-4.7 \%$ of the lymphocytes in the freshly isolated PBMNCs in the starting culture. On day +10 , the $\mathrm{CD}^{+} \mathrm{CD} 6^{+}$subset of cells was significantly expanded in the range of $28 \%$ to $50 \%$, with a median of $37 \%$.

The cytotoxic effect of expanded CIK cells was verified by performing a cytotoxicity assay against the CFSE-labeled target K562 cells. The K562 cells in a 20:1 E:T ratio were not distinct in the ungated forward scatter (FSC)/ side scatter (SSC) dot plot shown in Figure 4. To quantitate specific lysis, flow cytometry analysis was performed in two steps: (1) selection of target cells on the SSC/CFSE dot plot, distinguishable from effector cells by their CFSE-positivity (Figure 4B); and (2)
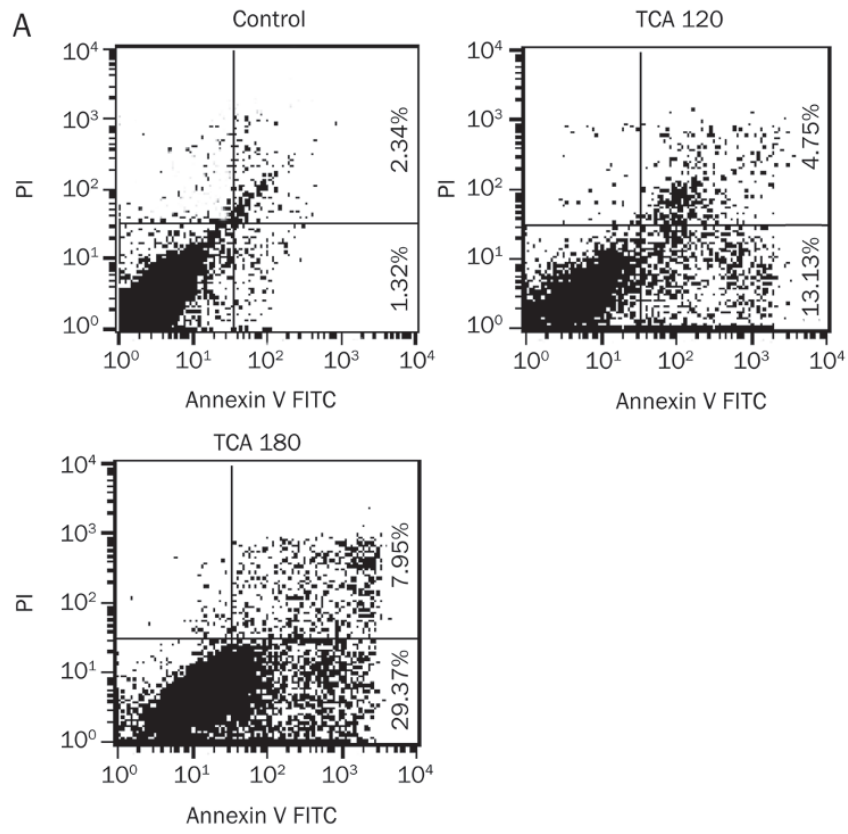

B

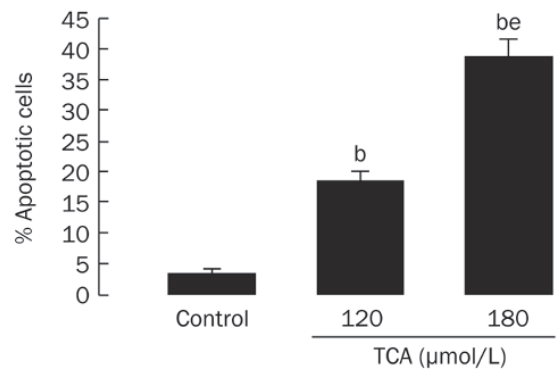

Figure 2. TCA induced significant apoptosis in K562 cells in a dosedependent manner at $24 \mathrm{~h}$. A) Original flow cytometry data. Medium supplemented with $0 \mu \mathrm{mol} / \mathrm{L}$ TCA (Control); Medium supplemented with $120 \mu \mathrm{mol} / \mathrm{L}$ TCA (TCA 120); Medium supplemented with $180 \mu \mathrm{mol} / \mathrm{L}$ TCA (TCA 180). B) Percentage of apoptosis in K562 cells. $n=6$. Mean \pm SD. ${ }^{\mathrm{b}} \mathrm{P}<0.05$ vs Control. ${ }^{\mathrm{e}} \mathrm{P}<0.05$ vs $120 \mu \mathrm{mol} / \mathrm{L}$ TCA.

determination of the percentage of target lysis, corresponding to the percentage of $\mathrm{CFSE}^{+} \mathrm{PI}^{+}$cells (sample lysis) in the presence of effectors at a given E:T ratio (Figure 4C). In parallel, basal lysis was quantified, corresponding to the percentage of dead K562 target cells in the absence of both CIK cells and TCA. The percentage of specific lysis for a given E:T ratio was calculated as follows:

$$
\% \text { Specific lysis }=\frac{\% \text { Sample lysis }-\% \text { Basal lysis }}{1-\% \text { Basal lysis }}
$$

Measurable cytotoxicity was observed at the effector:target ratio of $25: 1$ and $50: 1$, with a mean specific lysis rate of $34.84 \% \pm 2.13 \%$ and $49.26 \% \pm 3.22 \%$, respectively (Figure 5).

After the above experiments, we evaluated the combined effects of CIK cells and TCA on K562 cells. To exclude the influence of TCA alone on the K562 cells, we pretreated target 

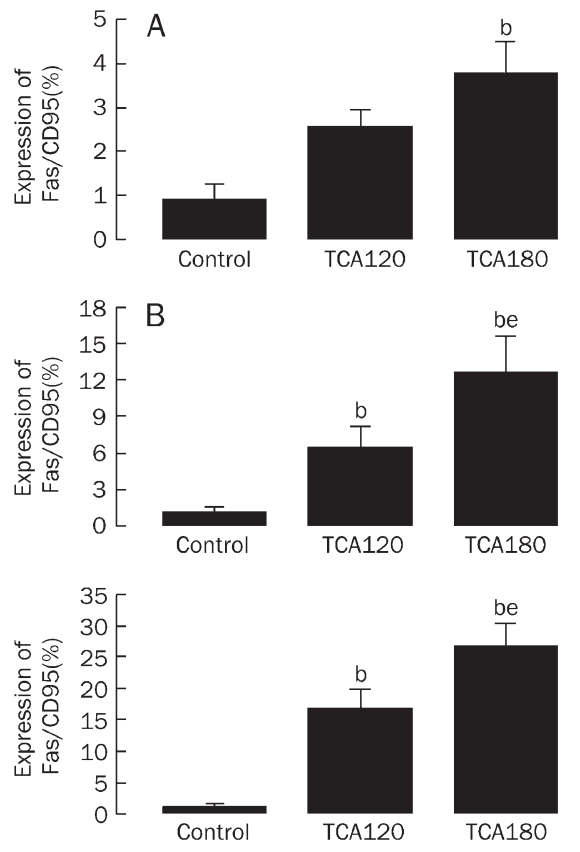

Figure 3. TCA upregulated expression of Fas/CD95 in K562 cells. A) Effect of TCA treatment for $4 \mathrm{~h}$ on expression of Fas/CD95 in K562 cells. B) Effect of TCA treatment for $9 \mathrm{~h}$ on expression of Fas/CD95 in K562 cells. C) Effect of TCA treatment for $24 \mathrm{~h}$ on expression of Fas/CD95 in K562 cells. $n=5$. Mean \pm SD. ${ }^{b} P<0.05$ vs Control. ${ }^{e} P<0.05$ vs $120 \mu \mathrm{mol} / \mathrm{L}$ TCA.
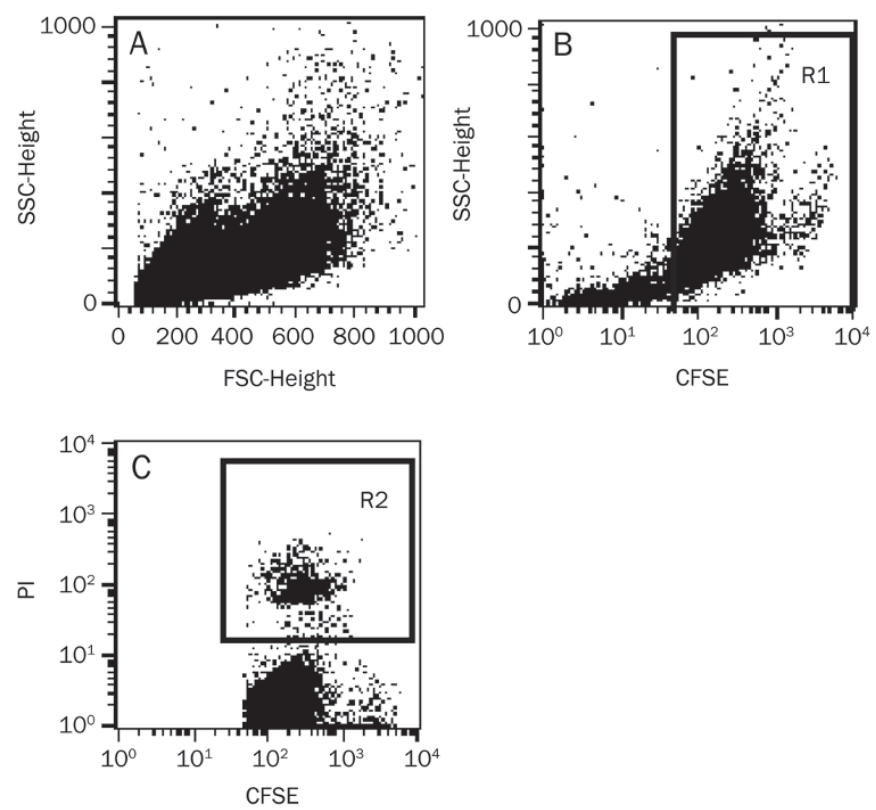

Figure 4. Lysis quantitation by the CFSE/PI assay. A) K562 cells are not distinct in the ungated FSC/SSC dot plot. B) Selection of K562 target cells (R1 gate) according to their CFSE-positivity on the SSC/CFSE dot plot. C) Quantitation of target cell lysis on the CFSE/PI dot plot. Dead K562 cells (R2 gate) are positive for both PI and CFSE.

cells with 0,120 , or $180 \mu \mathrm{mol} / \mathrm{L}$ TCA for $4 \mathrm{~h}$ and then washed the TCA out or continued to treat with 120 or $180 \mu \mathrm{mol} / \mathrm{L}$
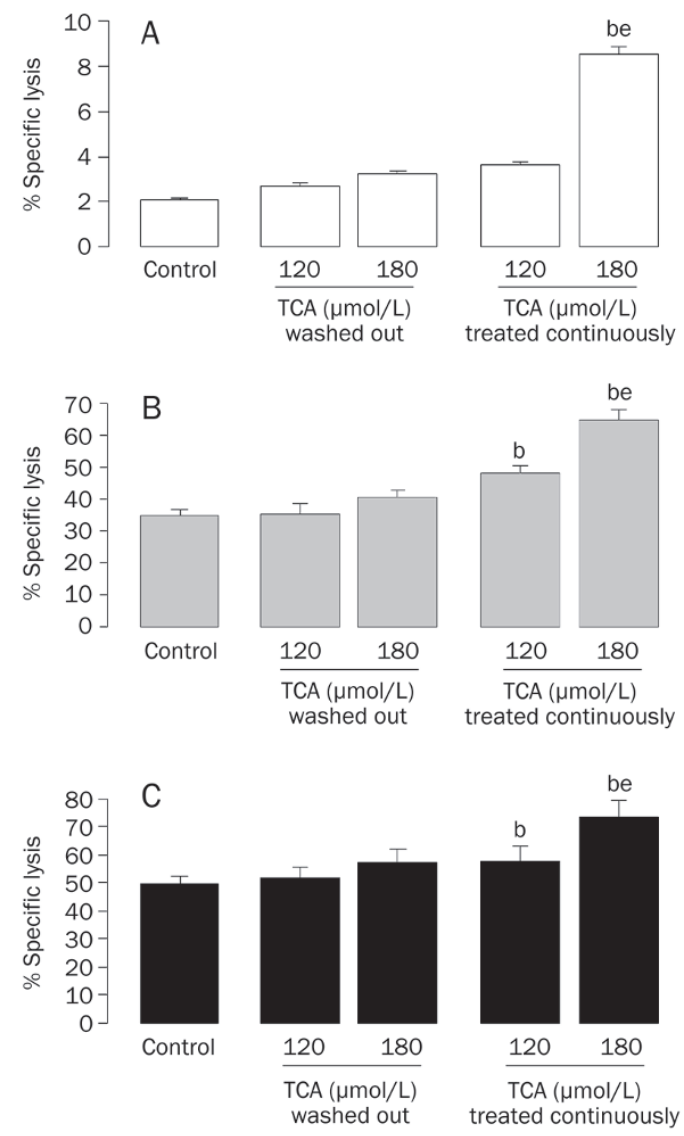

Figure 5. TCA synergized the cytotoxicity of ClK cells to K562 cells. A) Effect of TCA on cytotoxic activity by CIK cells to K562 cells at the indicated effector:target ratio of 0:1. B) Effect of TCA on cytotoxic activity by CIK cells to K562 cells at the indicated effector: target ratio of 25:1. C) Effect of TCA on cytotoxic activity by ClK cells to K562 at the indicated effector: target ratio of 50:1. $n=5$. Mean \pm SD. ${ }^{\mathrm{b}} P<0.05$ vs Control. ${ }^{e} P<0.05$ vs $120 \mu \mathrm{mol} / \mathrm{L}$ TCA treated continuously. TCA washout group: target cells were pretreated with TCA for $4 \mathrm{~h}$ and then washed out in the presence of CIK cells. TCA continuously treated group: target cells were pretreated with TCA for $4 \mathrm{~h}$ and then for another $5 \mathrm{~h}$ in the presence of ClK cells.

TCA for another $5 \mathrm{~h}$ in the presence of CIK cells. The effect of CIK cells on K562 cells in TCA washed out groups showed no significant difference to that of TCA untreated groups at the two tested E:T ratios. When target cells were continuously treated with TCA, specific lysis was increased compared to corresponding partners. TCA at 120 and $180 \mu \mathrm{mol} / \mathrm{L}$ induced the specific lysis of CIK cells are rates of $48.21 \% \pm 2.22 \%$ and $64.81 \% \pm 3.22 \%$, respectively, at the E:T ratio of $25: 1$ and of $57.81 \% \pm 5.13 \%$ and $73.36 \% \pm 5.98 \%$, respectively, at the E:T ratio of $50: 1$.

\section{Discussion}

K562 cells were the first established human immortalized myelogenous leukemia line. These cells are of the erythroleukemia type and are derived from a 53-year old female patient with chronic myeloid leukemia (CML) in blast crisis. In cul- 
ture, K562 cells exhibit much less clumping than many other suspension lines. K562 cells can spontaneously develop characteristics similar to early-stage erythrocytes, granulocytes and monocytes and are easily killed by natural killer (NK) cells as they lack the MHC complex required to inhibit NK activity. Thus, K562 cells were chosen to explore the cytotoxic effects of TCA in this study.

Our data show that TCA induces apoptosis of human myeloid leukemia K562 cells, upregulates Fas/CD95 expression, decreases mitochondrial transmembrane potential $(\Delta \psi \mathrm{m})$ in the treated $\mathrm{K} 562$ cells and synergizes the cytotoxicity of CIK cells to K562 cells. These data suggest TCA may trigger the extrinsic or Fas-mediated apoptotic pathway in K562 cells as well as the intrinsic or mitochondrial-mediated apoptotic pathway.

Cell apoptotic pathways commonly include the Fas and mitochondrial-mediated apoptotic pathway ${ }^{[1]}$. The Fas receptor is the most intensely studied death receptor. Fas forms the death inducing signaling complex (DISC) upon ligand binding. Membrane-anchored Fas ligand trimer on the surface of an adjacent cell causes trimerization of the Fas receptor. The extrinsic Fas pathway is sufficient to induce complete apoptosis in certain cell types through DISC assembly and subsequent caspase- 8 activation. It is well known that the Fas/Fas ligand (FasL) pathway is an alternative effector mechanism used by CIK cells to lyse their target cells ${ }^{[12,13]}$. CIK cells synthesize FasL and CIK culture supernatants contain biologically active soluble FasL ${ }^{[14]}$. Cytotoxicity was blocked by the addition of anti-Fas $\mathrm{mAb}^{[15]}$. A subset of CIK cells may induce an advantageous Th1-dominance microenvironment, inducing tumor apoptosis through the Fas/FasL pathway causing antitumor cytotoxicity in vivo ${ }^{[16]}$.

CIK cells are MHC-unrestricted cytotoxic lymphocytes with the characteristic $\mathrm{CD}^{+} \mathrm{CD} 56^{+}$phenotype. They are generated from peripheral blood lymphocytes and represent a rare subset of circulating lymphocytes (from $1 \%$ to $5 \%$ of peripheral blood lymphocytes $)^{[17]}$. At maturity, CIK cells exhibit potent cytotoxicity against autologous acute myeloid leukemia (AML) targets, as well as against allogeneic myeloid leukemia cells, regardless of the HLA types of these targets. It has also been reported that CIK cells are cytolytic against CML cells, both in vitro and in the SCID mouse tumor model ${ }^{[18]}$. Donor generated CIK cells do not induce GVHD as observed for unfractionated donor splenocytes, and they prolong the survival of murine leukemia-bearing mice. Therefore, the use of CIK cells in immunotherapy to eradicate resistant residual tumor cells with limited toxicity against normal cells is very promising ${ }^{[19]}$. In the present study, TCA upregulated the expression of Fas, indicating the Fas/FasL pathway may be involved in apoptosis by TCA and in the enhanced cytotoxicity triggered by CIK cells.

TCA, a drug with immunomodulatory and antitumor characteristics, was shown to induce apoptosis of K562 cells by Fas and mitochondrial-mediated apoptotic pathway. TCA synergized the cytotoxic capability of CIK cells against K562 target cells, perhaps via the upregulation of Fas on the target cells. If the combination of CIK cells and TCA can be used clinically, they may synergistically act on malignant cells in a manner that is beneficial to patients.

Current treatment strategies in adult patients with AML lead to complete remission (CR) in $50 \%-80 \%$ of the patients. Additionally, more than $80 \%$ of childhood and $35 \%$ of adult acute lymphoblastic leukemia (ALL) patients are cured with modern chemotherapy supplemented with $\mathrm{HSCT}^{[20]}$. Despite major progress in treating hematologic malignancies, much work remains ahead. Some of these patients will eventually relapse due to the persistence of residual leukemic cells that escape the cytotoxic effects of therapy ${ }^{[21]}$. Occasionally, routine radiation and chemotherapy used to treat leukemia are both unable to eradicate the residual and metastatic leukemic cells. Thus, with the exception of graft-versus-leukemia (GVL) effect, there are not many treatment options available today to eradicate residual malignant cells. However, GVL effect is mediated by GVHD, a potentially dangerous and usually mortal condition often developed by patients following HSCT $^{[22]}$. Therefore, it is necessary to develop new strategies to treat patients post-HSCT.

In conclusion, TCA has cytotoxic effects on human leukemia K562 cells by inducing apoptosis and synergizing the cytotoxicity of CIK to K562 cells. These properties of TCA may be beneficial in treatment of leukemia, even in post-HSCT patients.

\section{Acknowledgements}

This project was supported by the National Outstanding Young Investigator Program of China (№ 30225038).

\section{Author contribution}

Jia-Hua ZHANG, Li-qiong LIU, Wei-jia KONG, Shi-ang HUANG designed research; Li-qiong LIU, Jia-Hua ZHANG, Yan-li HE performed research; Jia-Hua ZHANG, Li-qiong LIU, Shi-ang HUANG analyzed data. Jia-Hua ZHANG, Li-qiong LIU, Wei-jia KONG, Shi-ang HUANG wrote the paper.

\section{References}

1 Ringdén 0. Immunotherapy by allogeneic stem cell transplantation. Adv Cancer Res 2007; 97: 25-60.

2 Nencioni A, Grünebach F, Patrone F, Ballestrero A, Brossart P. Proteasome: inhibitors antitumor effects and beyond. Leukemia 2007; 21: 30-6.

3 Ka H, Park HJ, Jung HJ, Choi JW, Cho KS, Ha J, et al. Cinnamaldehyde induces apoptosis by ROS-mediated mitochondrial permeability transition in human promyelocytic leukemia HL-60 cells. Cancer Lett 2003; 196: 143-52.

4 Lee CW, Lee SH, Lee JW, Ban JO, Lee SY, Yoo HS, et al. 2-hydroxy cinnamaldehyde inhibits SW620 colon cancer cell growth through AP-1 inactivation. J Pharmacol Sci 2007; 104: 19-28.

5 Koh WS, Yoon SY, Kwon BM, Jeong TC, Nam KS, Han MY. Cinnamaldehyde inhibits lymphocyte proliferation and modulates T-cell differentiation. Int J immunopharmacol 1998; 20: 643-60.

6 Baker J, Verneris MR, Ito M, Shizuru JA, Negrin RS. Expansion of cytolytic $\mathrm{CD} 8(+)$ natural killer T cells with limited capacity for graftversus-host disease induction due to interferon gamma production. 
Blood 2001; 97: 2923-31.

7 Introna M, Borleri G, Conti E, Franceschetti M, Barbui AM, Broady R, et al. Repeated infusions of donor-derived cytokine-induced killer cells in patients relapsing after allogeneic stem cell transplantation: a phase I study. Haematologica 2007; 92: 952-59.

8 Tam YK, Martinson JA, Doligosa K, Klingemann HG. Ex vivo expansion of the highly cytotoxic human natural killer-92 cell-line under current good manufacturing practice conditions for clinical adoptive cellular immunotherapy. Cytotherapy 2003; 5: 259-72.

9 Cholujová D, Jakubíková J, Kubes M, Arendacká B, Sapák M, Innatko $\mathrm{R}$, et al. Comparative study of four fluorescent probes for evaluation of natural killer cell cytotoxicity assays. Immunobiology 2008; 213: 629-40.

10 Zamai L, Ahmad M, Bennett IM, Azzoni L, Alnemri ES, Perussia B. Natural killer (NK) cell-mediated cytotoxicity: differential use of TRAIL and Fas ligand by immature and mature primary human NK cells. J Exp Med 1998; 188: 2375-80.

11 Ueda S, Masutani H, Nakamura H, Tanaka T, Ueno M, Yodoi J. Redox control of cell death. Antioxid Redox Signal 2002; 4: 405-14.

12 Kägi D, Vignaux F, Ledermann B, Bürki K, Depraetere V, Nagata S, et al. Fas and perforin pathways as major mechanisms of $T$ cellmediated cytotoxicity. Science 1994; 265: 528-30.

13 Lowin B, Hahne M, Mattmann C, Tschopp J. Cytolytic T-cell cytotoxicity is mediated through perforin and Fas lytic pathways. Nature 1994; 370: 650-52.

14 Verneris MR, Kornacker M, Mailänder V, Negrin RS. Resistance of ex vivo expanded $\mathrm{CD}^{+} \mathrm{CD} 6^{+} \mathrm{T}$ cells to Fas-mediated apoptosis. Cancer
Immunol Immunother 2000; 49: 335-45.

15 Li W, Wang S, Chen C, Zhuang G. Induction of tumor cell apoptosis via Fas/DR5. Cell Mol Immunol 2006; 3: 467-71.

16 Yu J, Ren X, Cao S, Zhang W, Hao X. Th1 polarization and apoptosisinducing activity of $\mathrm{CD} 4^{+} \mathrm{T}$-cells in cytokine-induced killers might favor the antitumor cytotoxicity of cytokine-induced killers in vivo. Cancer Biother Radiopharm 2006; 21: 276-84.

17 Leemhuis T, Wells S, Scheffold C, Edinger M, Negrin RS. A phase I trial of autologous cytokine-induced killer cells for the treatment of relapsed Hodgkin disease and non-Hodgkin lymphoma. Biol Blood Marrow Transplant 2005; 11: 181-7.

18 Linn YC, Hui KM. Cytokine-induced killer cells: NK-like T cells with cytotolytic specificity against leukemia. Leuk Lymphoma 2003; 44: 1457-62.

19 Shi M, Zhang B, Tang ZR, Lei ZY, Wang HF, Feng YY, et al. Autologous cytokine-induced killer cell therapy in clinical trial phase I is safe in patients with primary hepatocellular carcinoma. World J Gastroenterol 2004; 10: 1146-51.

20 Wang ZY, Chen Z. Acute promyelocytic leukemia: from highly fatal to highly curable. Blood 2008; 111: 2505-15.

21 Torelli GF, Guarini A, Maggio R, Alfieri C, Vitale A, Foà R. Expansion of natural killer cells with lytic activity against autologous blasts from adult and pediatric acute lymphoid leukemia patients in complete hematologic remission, Haematologica 2005; 90: 785-92.

22 Szczepański T. Why and how to quantify minimal residual disease in acute lymphoblastic leukemia? Leukemia 2007; 21: 622-26. 